\title{
Principal Component Analysis of Birth Weight of Child, Maternal Pregnancy Weight and Maternal Pregnancy Body Mass Index: A Multivariate Analysis
}

\author{
Kindu Kebede Gebre \\ Department of Statistics, College of Computing and Informatics, Haramaya University, Harar, Ethiopia \\ Email address: \\ m7.kebede@gmail.com,kindu_keede@yahoo.com \\ To cite this article: \\ Kindu Kebede Gebre. Principal Component Analysis of Birth Weight of Child, Maternal Pregnancy Weight and Maternal Pregnancy Body \\ Mass Index: A Multivariate Analysis. American Journal of Theoretical and Applied Statistics. Vol. 10, No. 1, 2021, pp. 63-71. \\ doi: $10.11648 /$ j.ajtas.20211001.17
}

Received: October 19, 2020; Accepted: October 28, 2020; Published: February 23, 2021

\begin{abstract}
Background: Birth weight, maternal body mass index and maternal weight is perhaps the most important and reliable indicator for neonatal and infant survival as well as their physical growth and mental development. The main objective of this study was identifying the determinants of birth weight, maternal body mass index and maternal weight simultaneously based on Ethiopia demographic health survey 2016 which implemented in statistical package R. Methods: Cross sectional study design was used from Ethiopia demographic health survey 2016. From principal component model shows the total population variance of first two components were $97 \%$ of the variation then the two components replace the original three responses variables birth weight, maternal body mass index and maternal weight without much loss of information. Therefore bi-variate linear regression model was used to identify factors that affect the first two principal components of birth weight, maternal body mass index and maternal weight simultaneously. Results: This study shows family size, region, frequency of read newspaper, frequency of watch television and preferred waiting time for birth were statistically significant at 5\% level of significance for first principal component. In addition, size of child, region and maternal age group are statistically significant for second principal components of birth weight of child, maternal pregnancy weight and maternal pregnancy body mass index in Ethiopia. Conclusion: From this finding family size, region, frequency of read newspaper, and frequency of watch television, size of child, maternal age group and preferred waiting time were significant predictors of the first two principal components simultaneously. Hence,-intervention should be given to the pregnant during antenatal care for minimizing the risk.
\end{abstract}

Keywords: Birth Weight, Maternal Weight, Maternal Body Mass Index, Bi-variate Model, Principal Component, Ethiopia Demographic Health Survey

\section{Introduction}

Birth weight, maternal body mass index and maternal weight is one of the most important and reliable determinant of neonatal and infant survival as well as their physical growth and mental development. Study by Ronnenberg et.al reported that maternal nutritional status is important to maternal and fetal wellbeing and BMI were influenced by ethnicity and genetics [1].

According to Akgun et.al reported shown that nutrient intake and weight gain during pregnancy are the two main factors affecting maternal and infant outcomes [2].

The study by Dönmez et.al reported that women gained excess weight during pregnancy and before pregnancy which causes to obesity. The rapid increase of obesity prevalence especially among women in the World cause women begins pregnancy overweight or obese and this can cause problems about pregnancy and birth [3].

A study by Restrepo-Méndez et.al discovered U-shaped relationship between age and low birth weight [4]. The study by Auger et.al concluded that rural relative to urban area as well as low socio-economic status (represented by maternal education) as having an association with low birth weight [5].

Globally, out of 139 million live births, about 20 million of them are low birth weight and nearly $95.6 \%$ of them are in developing countries. According to Ethiopian Demographic 
and Health Survey, 2011, only 5\% of children were weighed at birth.

Study conducted in Scotland from 2002 to 2004 shown that the $20 \%$ of women who received antenatal care were obese that representing a twofold increase over the past 10 years [9]. A similar study conducted in United States shown that women who received antenatal care increased from $16 \%$ to $36 \%$ from 1980 to 1999 [10]. Babies who born in SubSaharan Africa (SSA) with LBW are 13\% for each year [6, 7]. Babies who born in Ethiopia with low birth weight are 13-11\% [8]. Gestational weight gain is also higher than ever before, with approximately $40 \%$ of pregnant women gaining more weight than is recommended [11]. Obesity during pregnancy may cause adverse outcomes, not only in the mother but also in the child.

\section{Study Design and Methods}

Cross-sectional study was conducted to identify directions along which predictor variables determine the most variation of birth weight, pregnancy weight and pregnancy body mass index. This study was identifying factors that have maximum effects on pregnancy and its outcome simultaneously with chronically order.

Study Area and Population

This study carried out in Ethiopia based on demographic and health survey 2016 which included pregnant women who participated on it.

\section{Data Collection Procedures}

This research utilized Ethiopia 2016 demography and health survey as its source of data that is the fourth comprehensive and nationally representative population and health survey. It is important feature of the data set that avails in-depth information on demographic and health aspects of households. The data would be collected by the central statistical agency at the request of the ministry of health [8]. Data collection took place from January 18, 2016, to June 27, 2016.

Inclusionand Exclusion Criteriaof the Study

Mothers who are pregnant and remember her child birth weight, pregnancy weight and body mass index which record from January18, 2016, toJune27, 2016 would be include in the study. Therefore, this study was including 1996 pregnant.

Variables Included in the Study

Response Variables

This study used child birth weight, pregnancy maternal weight and pregnancy body mass index as response variables.

Explanatory Variables

The predictor variables to be studied as determinants of child birth weight, maternal weight and maternal body mass index simultaneously would be included number of tetanus injections before pregnancy, age group, family size, frequency of watch tv, preferred wait time, husband educational level, frequency of reading newspaper or magazine, desire for more children, size of child at birth and region.

Table 1. Description of variables in the study

\begin{tabular}{|c|c|}
\hline Variables & Factor Categories \\
\hline \multirow{3}{*}{ Region } & $1=$ Tigray, $2=$ Afar, $3=$ Amhara, $4=$ Oromo \\
\hline & $5=$ Somali, $6=$ Benishangul, $7=$ SNNPR, $8=$ Gambela \\
\hline & 9=Harari, $10=$ Addis Adaba,11=Dire Dawa \\
\hline \multirow{2}{*}{ Tetanus injection before pregnancy } & $0=$ no, $1=1-3$ times, $2=4-6$ times \\
\hline & $3=>7$ times, $4=$ did not known \\
\hline \multirow{3}{*}{ Desire for more children } & $1=$ Wants within 2 years, $2=$ Wants after $2^{+}$years \\
\hline & $3=$ Wants, unsure timing, $4=$ Undecided \\
\hline & $7=$ Declared infecund, $8=$ never had sex \\
\hline \multirow{3}{*}{ Size of Child at Birth } & $1=$ Very large, $2=$ Larger than average \\
\hline & $3=$ Average, $4=$ Smaller than average \\
\hline & $5=$ very small, $8=$ not known \\
\hline Age groups & $1=15-19,2=20-24,3=25-29,4=>30$ years \\
\hline Preferred waiting time for birth & $\begin{array}{l}0=<12 \text { months, } 1=1 \text { year }, 2=2 \text { year, } 3=3 \text { year, } 4=4 \text { year } \\
5=5 \text { year, } 6=6 \text { year, } 7=7 \text { year }, 8=8 \text { year }\end{array}$ \\
\hline Husband Educational Level & $0=$ no education, $1=$ primery, $2=$ secondary, $3=$ higher, $4=$ don't known \\
\hline Frequency of watch TV & $0=$ no, $1=$ Less than once a week, $2=$ At least once a week, $3=$ always \\
\hline Family size & Continuous \\
\hline
\end{tabular}

\section{Principal Component Analysis}

A principal component analysis is concerned with explaining the variance-covariance structure of a set of variables through a few linear combinations of these variables. It is one of a family of techniques for taking highdimensional data, and using the dependencies between the variables to represent it in a more tractable, lowerdimensional form, without losing too much information. PCA is one of the simplest and most robust ways of doing such dimensionality reduction. Principal component analysis (PCA) is a multivariate technique that analyzes a datatable in which observations are described by several inter-correlated quantitative dependent variables.

Goals of Principal Component Analysisunder this study, we will used PCA are:-

To extract the most important information from the data table.

To compress the size of the data set by keeping only this important information. 
To simplify the description of the data set.

To analyze the structure of the observations and the variables.

In order to achieve these goals, PCA computes new variables called principal componentswhich are obtained as linear combinations of the original variables. The first principal component is required to have the largest possible variance.

The second component is computed under the constraint of being orthogonal to the first componentand to have the largest possible inertia. The other components are computed likewise. The values of these new variables forthe observations are called factor scores, and these factors scores can be interpreted geometrically as the projectionsof the observations onto the principal components.

The Principal Component Model

If the observed variables are $\mathrm{Y}_{1}, \mathrm{Y}_{2}, \mathrm{Y}_{\mathrm{m}}$, and the new transformed variables of PCA are $\mathrm{PCA}_{l}, \mathrm{PCA}_{2}, \ldots, \mathrm{PCA}_{m}$ then the variables may be expressed as linear functions of the PCA:

$$
\begin{gathered}
\mathrm{PCA}_{1}=\mathrm{e}_{11} \mathrm{Y}_{1}+\mathrm{e}_{12} \mathrm{Y}_{2}+\mathrm{e}_{13} \mathrm{Y}_{3}+\ldots+\mathrm{e}_{1 \mathrm{~m}} \mathrm{Y}_{\mathrm{m}} \\
\mathrm{PCA}_{2}=\mathrm{e}_{21} \mathrm{Y}_{1}+\mathrm{e}_{22} \mathrm{Y}_{2}+\mathrm{e}_{23} \mathrm{Y}_{3}+\ldots+\mathrm{e}_{2 \mathrm{~m}} \mathrm{Y}_{\mathrm{m}} \\
\ldots \\
\mathrm{PCA}_{\mathrm{n}}=\mathrm{e}_{\mathrm{n} 1} \mathrm{Y}_{1}+\mathrm{e}_{\mathrm{n} 2} \mathrm{Y}_{2}+\mathrm{e}_{\mathrm{n} 3} \mathrm{Y}_{3}+\ldots+\mathrm{e}_{\mathrm{nm}} \mathrm{Y}_{\mathrm{m}}
\end{gathered}
$$

$\mathrm{PCA}_{\mathrm{i}}$ are uncorrelated, $\mathrm{PCA}_{1}$ explain as much as possible of original variance in the dataset and $\mathrm{PCA}_{2}$ explain the remaining variance of the original data set etc.The equation(1) shows small set of linear combinations of the covariates which are uncorrelated with each other.This will avoid the multicollinearity problem. However the linear combinations chosen have maximal variance. A good regression design chooses values of the covariates which are spread out.

$$
\begin{aligned}
\operatorname{Var}\left(\mathrm{PCA}_{\mathrm{i}}\right)= & \mathrm{a}^{\prime} \sum \mathrm{a} \mathrm{i}=1,2, \ldots, \mathrm{n} \\
\operatorname{Cov}\left(\mathrm{PCA}_{\mathrm{i}}, \mathrm{PCA}_{\mathrm{k}}\right) & =\mathrm{a}^{\prime} \sum \mathrm{aki}, \mathrm{k}=1,2, \ldots, \mathrm{n} \\
e_{\mathrm{i}} & =\left[\begin{array}{c}
e_{1 i} \\
e_{2 i} \\
\cdot \\
e_{n i}
\end{array}\right]
\end{aligned}
$$

Estimation of principal components coefficients

To estimate the coefficients from principal components first estimate the variance for $i^{\text {th }}$ principal components is equal to $i^{\text {th }}$ eigenvalue.

$$
\begin{gathered}
\operatorname{Var}\left(\mathrm{PCA}_{\mathrm{i}}\right)=\operatorname{var}\left(\mathrm{e}_{\mathrm{i} 1} \mathrm{Y}_{1}+\mathrm{e}_{\mathrm{i} 2} \mathrm{Y}_{2}+\mathrm{e}_{\mathrm{i} 3} \mathrm{Y}_{3}+\ldots+\mathrm{e}_{\mathrm{im}} \mathrm{Y}_{\mathrm{m}}\right)=\lambda_{\mathrm{i}} \\
\operatorname{Cov}\left(\mathrm{PCA}_{\mathrm{i}}, \mathrm{PCA}_{\mathrm{k}}\right)=0
\end{gathered}
$$

The eigenvalue of variance covariance matrix $\sum$ and the corresponding eigenvectors $e_{1}$ through $e_{n}$ will be principal component coefficients. However the order of eigenvalue or variance is $\lambda_{1} \geq \lambda_{2} \ldots, \geq \lambda_{n}$. The eigenvalues and eigenvectors 3. Statistical Results of covariance matrix differ from those of the associated correlation matrix. Therefore PCA of covariance matrix is meaningful only if the variance expressed in the same units, and PCA of correlation matrix to be use when variables on different scales.

Proportion of total population variance of principal components Analysis

Proportion of total variance due to $\mathrm{k}^{\text {th }}$ components is equal to

$$
\frac{\lambda_{k}}{\lambda_{1}+\lambda_{2, \ldots, \lambda_{n}}} . \mathrm{k}=1,2, \ldots ., \mathrm{n}
$$

Proportion of total variance due to first $\mathrm{k}^{\text {th }}$ components is equal to $\frac{\lambda_{k+\lambda_{2}+\cdots+\lambda_{k}}}{\lambda_{1}+\lambda_{2, \cdots,+\lambda_{n}}} \cdot \mathrm{k}=1,2, \ldots, \mathrm{n}$

In order to decide how many principal components should be retained, it is common to summarize the results of a principal components analysis by proportion of total variance.

If most (for instance, $80 \%$ to $90 \%$ ) of total population variance for large $n$, can be attribute to the first one, two, three then these components replace the original $n$ variables without much loss of information [13].

The correlation between component and variables

The correlation between components $\mathrm{PCA}_{i}$, and the variable $\mathrm{Y}_{\mathrm{k}}$ are:

$$
\rho p c a_{i}, y_{k}=\frac{e_{i k} \sqrt{\lambda_{i}}}{\delta_{k k}}
$$

Multivariate Multiple Linear Regression Models

This study usedmultivariate multiple linear regression models after perform PCAthen we have $\mathrm{p}>1$ predictors and $\mathrm{m}>1$ response variables. Furthermore, the response variable is linear function of parameters $\left(b_{0}, b_{1}, b_{2}, \ldots, b_{p}\right.$ are parameters).

Each response is assumed to follow its own regression model, so that

$$
\mathrm{Y}=\mathrm{X} \beta+€
$$

where $\beta^{\prime}=\left\{b_{0}, b_{1}, b_{2}, \ldots, b_{p}\right\}, \varepsilon^{\prime}=\left\{\varepsilon_{1}, \varepsilon_{2} \ldots \varepsilon_{m}\right\}$ has $\mathrm{E}(\varepsilon)=0$ and $\operatorname{var}(\varepsilon)=\sum$. Thus, the error terms associated with different responses on the same trial are correlated.

The parameters value is obtained from parameter estimation. According to Nkurunziza et.al reported the mostly used estimation methods are the multivariate least squares estimation [12].Under this study we used backward elimination. There are also different model diagnostic frameworks for identifying, analyzing and interpreting data in a given context to identify possible needs.A first step of the regression diagnostic is to inspect the significancy of the regression beta coefficients, as well as, the coefficients of determination $\left(\mathrm{R}^{2}\right)$ that tells us how well the linear regression model fit to the data. For this study we used plots of residuals vs fitted, Normal Q-Q and scale location (spread-location). 
Table 2. Descriptive Statistics.

\begin{tabular}{|c|c|c|c|c|c|c|c|c|c|c|}
\hline & & \multicolumn{3}{|c|}{ Maternal Weight ( kg) } & \multicolumn{3}{|c|}{ Body Mass Index $\left(\mathrm{kg} / \mathrm{m}^{2}\right)$} & \multicolumn{3}{|c|}{ Birth Weight (kg) } \\
\hline & & Mean & SD & SE & Mean & SD & SE & Mean & SD & SE \\
\hline \multirow{11}{*}{ Region } & Tigray & 50.11 & 8.02 & .48 & 20.31 & 2.92 & .18 & 3.30 & .78 & .05 \\
\hline & Afar & 53.22 & 11.83 & 1.92 & 21.77 & 4.44 & .72 & 3.03 & .96 & .16 \\
\hline & Amhara & 52.45 & 10.29 & 1.13 & 21.27 & 3.75 & .41 & 3.00 & .87 & .10 \\
\hline & Oromia & 53.31 & 9.24 & .80 & 21.62 & 3.63 & .32 & 3.35 & 1.05 & .09 \\
\hline & Somali & 64.73 & 16.47 & 1.37 & 24.36 & 5.76 & .48 & 3.31 & .93 & .08 \\
\hline & Benishangul & 52.07 & 8.10 & .66 & 21.04 & 2.74 & .22 & 3.19 & .75 & .06 \\
\hline & SNNPR & 54.80 & 10.27 & .76 & 21.98 & 3.51 & .26 & 3.50 & 1.12 & .08 \\
\hline & Gambela & 54.72 & 8.86 & .68 & 20.37 & 3.72 & .29 & 3.18 & .80 & .06 \\
\hline & Harari & 57.02 & 11.15 & .78 & 22.99 & 4.16 & .29 & 3.43 & .72 & .05 \\
\hline & Addis Adaba & 61.61 & 11.45 & .58 & 24.84 & 4.22 & .21 & 3.16 & .66 & .03 \\
\hline & Dire Dawa & 59.34 & 13.22 & .89 & 23.65 & 5.04 & .34 & 3.30 & .76 & .05 \\
\hline \multirow{3}{*}{$\begin{array}{l}\text { Frequency of reading } \\
\text { newspaper or magazine }\end{array}$} & Not at all & 55.47 & 11.74 & .30 & 22.12 & 4.32 & .11 & 3.26 & .88 & .02 \\
\hline & $<1$ a week & 59.71 & 11.48 & .60 & 23.75 & 4.30 & .22 & 3.32 & .68 & .04 \\
\hline & $>=1$ a week & 60.13 & 11.86 & 1.11 & 23.82 & 4.53 & .42 & 3.33 & .72 & .07 \\
\hline \multirow{3}{*}{$\begin{array}{l}\text { Frequency of watching } \\
\text { TV }\end{array}$} & Not at all & 52.48 & 9.41 & .32 & 20.85 & 3.37 & .12 & 3.26 & .90 & .03 \\
\hline & $<1$ a week & 56.09 & 12.87 & .80 & 22.35 & 4.64 & .29 & 3.33 & .91 & .06 \\
\hline & $>=1$ a week & 60.45 & 12.29 & .41 & 24.13 & 4.55 & .15 & 3.27 & .73 & .02 \\
\hline \multirow{5}{*}{$\begin{array}{l}\text { Husband/partner's } \\
\text { education level }\end{array}$} & No education & 53.23 & 11.30 & .62 & 21.19 & 3.88 & .21 & 3.24 & .95 & .05 \\
\hline & Primary & 54.15 & 10.36 & .43 & 21.94 & 3.73 & .16 & 3.28 & .91 & .04 \\
\hline & Secondary & 58.47 & 12.18 & .57 & 23.15 & 4.75 & .22 & 3.25 & .71 & .03 \\
\hline & Higher & 60.17 & 12.31 & .59 & 23.69 & 4.71 & .23 & 3.30 & .76 & .04 \\
\hline & Don't know & 61.44 & 11.11 & 2.70 & 24.10 & 3.81 & .92 & 3.22 & .76 & .18 \\
\hline \multirow{6}{*}{ Size of child at birth } & Very large & 57.41 & 13.45 & .63 & 22.74 & 4.76 & .22 & 3.97 & .92 & .04 \\
\hline & Larger than average & 58.22 & 11.83 & .63 & 23.10 & 4.49 & .24 & 3.50 & .58 & .03 \\
\hline & Average & 55.81 & 11.13 & .38 & 22.29 & 4.20 & .14 & 3.12 & .57 & .02 \\
\hline & Smaller than average & 55.85 & 10.96 & .98 & 22.30 & 4.02 & .36 & 2.59 & .61 & .05 \\
\hline & Very small & 55.11 & 11.12 & .76 & 22.09 & 4.15 & .28 & 2.44 & .66 & .05 \\
\hline & Don't know & 40.90 & . & . & 17.16 & . & . & 3.10 & . & . \\
\hline \multirow{9}{*}{$\begin{array}{l}\text { Preferred waiting time } \\
\text { for birth of a/another } \\
\text { child (grouped) }\end{array}$} & $<12$ months & 61.07 & 12.99 & .97 & 23.50 & 4.90 & .36 & 3.30 & .87 & .06 \\
\hline & 1 year & 57.50 & 11.70 & 1.20 & 22.78 & 4.45 & .46 & 3.23 & .76 & .08 \\
\hline & 2 years & 58.39 & 13.28 & .93 & 23.16 & 4.98 & .35 & 3.29 & .84 & .06 \\
\hline & 3 years & 56.19 & 11.14 & .72 & 22.70 & 4.17 & .27 & 3.20 & .81 & .05 \\
\hline & 4 years & 54.75 & 9.79 & .82 & 21.80 & 3.70 & .31 & 3.17 & .83 & .07 \\
\hline & 5 years & 53.75 & 9.28 & .62 & 21.70 & 3.46 & .23 & 3.28 & .84 & .06 \\
\hline & $6+$ years & 53.21 & 9.55 & .78 & 21.54 & 3.76 & .30 & 3.21 & .80 & .06 \\
\hline & Non-numeric & 56.55 & 13.11 & 2.22 & 22.82 & 4.57 & .77 & 3.29 & 1.04 & .18 \\
\hline & Don't know & 60.92 & 17.09 & 2.55 & 23.84 & 5.47 & .82 & 3.42 & .91 & .14 \\
\hline \multirow{4}{*}{ Age in 5-year groups } & $15-19$ & 59.61 & 13.16 & 1.46 & 23.73 & 4.63 & .51 & 3.36 & .83 & .09 \\
\hline & $20-24$ & 56.59 & 11.89 & .55 & 22.75 & 4.52 & .21 & 3.21 & .81 & .04 \\
\hline & $25-29$ & 56.84 & 11.72 & .46 & 22.46 & 4.30 & .17 & 3.30 & .85 & .03 \\
\hline & $30+$ & 55.91 & 11.74 & .41 & 22.30 & 4.32 & .15 & 3.28 & .83 & .03 \\
\hline \multirow{8}{*}{ Desire for more children } & Wants within 2 years & 55.94 & 11.74 & .71 & 22.44 & 4.37 & .26 & 3.28 & .88 & .05 \\
\hline & Wants after $2+$ years & 56.71 & 11.90 & .38 & 22.62 & 4.39 & .14 & 3.26 & .83 & .03 \\
\hline & Wants, unsure timing & 57.47 & 11.35 & 1.27 & 22.58 & 4.17 & .47 & 3.31 & .77 & .09 \\
\hline & Undecided & 55.72 & 11.15 & 1.26 & 21.90 & 4.01 & .45 & 3.19 & .83 & .09 \\
\hline & Wants no more & 56.42 & 11.97 & .49 & 22.47 & 4.45 & .18 & 3.30 & .84 & .03 \\
\hline & Sterilized & 59.07 & 15.28 & 5.78 & 22.44 & 4.64 & 1.75 & 3.29 & .95 & .36 \\
\hline & Declared infecund & 57.06 & 8.17 & 3.65 & 21.06 & 4.22 & 1.89 & 3.10 & .22 & .10 \\
\hline & Never had sex & . & . & . & . & . & . & . & . & . \\
\hline \multirow{5}{*}{$\begin{array}{l}\text { Number of tetanus } \\
\text { injections before } \\
\text { pregnancy }\end{array}$} & Received no injection & 55.21 & 11.62 & .68 & 22.10 & 4.28 & .25 & 3.23 & .79 & .05 \\
\hline & $1-3$ & 56.68 & 12.28 & 1.00 & 22.36 & 4.50 & .37 & 3.36 & .80 & .07 \\
\hline & $4-6$ & 56.70 & 11.57 & 1.14 & 22.78 & 4.61 & .45 & 3.27 & .89 & .09 \\
\hline & $7+$ & 60.91 & 17.50 & 5.83 & 23.62 & 4.53 & 1.51 & 3.01 & .60 & .20 \\
\hline & Don't know & 53.52 & 8.53 & 1.38 & 21.68 & 4.13 & .67 & 3.48 & .92 & .15 \\
\hline
\end{tabular}

Table 2 results shows that the average and standard deviation of weight of mother who lived Somali and Tigray region is 64.73(16.47) and 50.11(8.02) kg respectively. In addition the average and standard deviation of body mass index of mother who lived Addis Ababa and Tigray region is $24.84(4.22)$ and $20.31(2.92) \mathrm{kg} / \mathrm{m}^{2}$ respectively. Furthermore, the average and standard deviation of birth weight of child who bornSNNP and Amhara region is 3.5 (1.12) and 3(0.87) 
$\mathrm{kg}$ respectively.

The mean and standard deviation of mother who is not read newspaper or magazine and who read more than or equal to 1times per a week were $55.47(11.74)$ and 60.13(11.86) $\mathrm{kg}$ respectively. Moreover, the mean and SD of body mass index who is read newspaper or magazine for more than or equal to 1 times pera week and not read at all were $23.82(4.53)$ and $22.12(4.32) \mathrm{kg} / \mathrm{m}^{2}$ respectively.

Mother who watch TV more than or equal to 1 times per a week and not watch at all had mean and SD of maternal weight were $60.45(12.29)$ and $52.48(9.41)$ respectively. In addition the mean and SD of maternal body mass index ofmother who watch TV more than or equal to 1 times per a week and not watch at all were 24.13(4.55) and 20.85(3.37) $\mathrm{kg} / \mathrm{m}^{2}$ respectively.

From size of child point of view, mother who had larger size of child and small size of child were higher and lower weight of mother respectively. The mean and SD of weight of mother who preferred less than 12 month and do not known the wait time for birth of other child were 61.07 (12.99) and $60.92(17.09) \mathrm{kg}$ respectively. Moreover, the mean and SD of birth weight of child born from mother who preferred 4 year and do not known the wait time for birth of other child were $3.17(0.83)$ and $3.42(0.91) \mathrm{kg}$ respectively. The mean of maternal weight, body mass index and birth weight of child for young mother is higher than old mother.

Furthermore, the mean of maternal weight and body mass index of mother who received more tetanus injection before pregnancy is higher but the mean of weight of child born from those mothers is lower. Under this study E-statistic of multivariate normality was used and it was show multivariate normality with $\mathrm{P}$ value equal to 0.25 . In addition residuals plot shown in Figure 2, indicate that the residuals and the fitted values confirm linearity without distinct patterns and shows constant variance and Figure 1 confirms normality of errors which was residual points follow the straight dashed line.

\section{Normal Q-Q Plot}

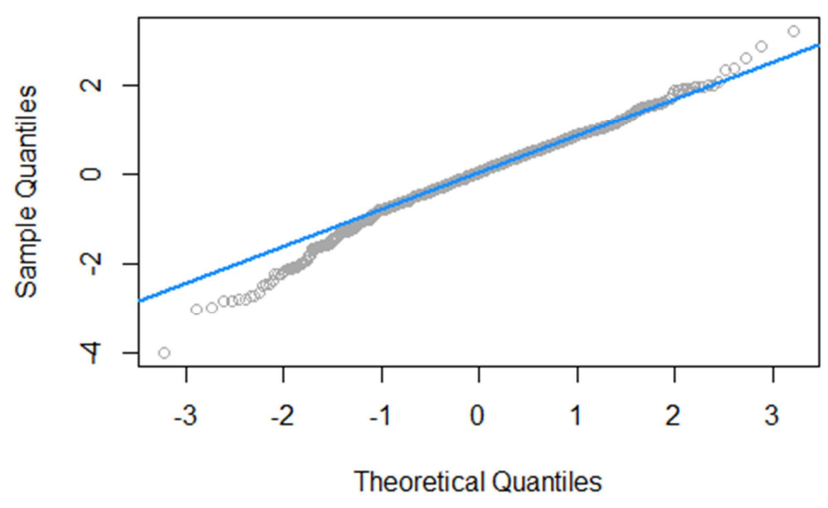

Figure 1. Normal $Q-Q$ plot.
Fitted vs Residual Plot

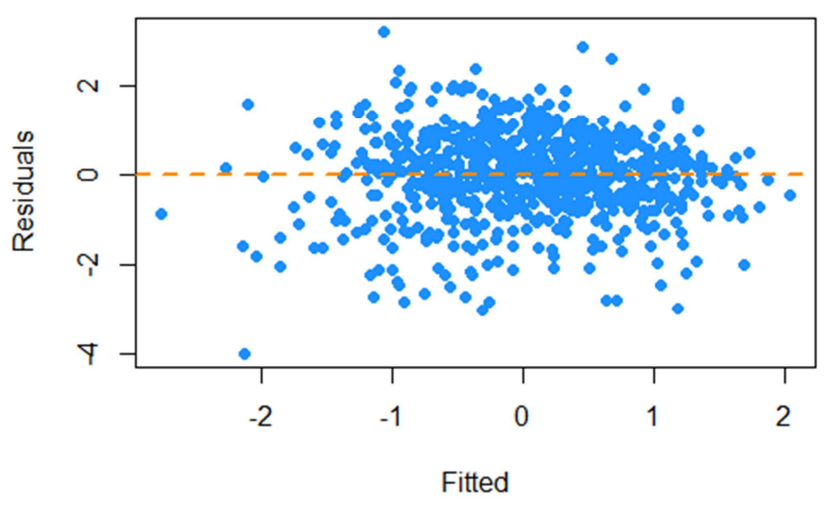

Figure 2. Residual plot.

Principal Component Analysis

Principal component analysis was a statistical procedure that uses an orthogonal transformation to convert a set of observations of possibly correlated variables into a set of values of linearly uncorrelated variables. Therefore we did the principal components of birth weight; body mass index and maternal weight with proportion to the total population variance of principal components are given in Table 3.

Table 3. Importance of Principal Components.

\begin{tabular}{llll}
\hline Statistic & $\mathbf{P C A}_{\mathbf{1}}$ & $\mathbf{P C A}_{\mathbf{2}}$ & $\mathbf{P C A}_{\mathbf{3}}$ \\
\hline Standard deviation & 1.39 & 1.00 & 0.29 \\
Proportion of Variance & 0.64 & 0.33 & 0.03 \\
Cumulative Proportion & 0.64 & 0.97 & 1 \\
\hline
\end{tabular}

Table 3 shows the first two components account for $97 \%$ of the variance and the bar plot for each component's variance (see Figure 3) shown how the first two components dominate. In order to achieve the goals of PCA computes new variables which were obtained as linear combinations of the original variables? The first and second principal component were required to have proportion of variance would be 0.64 and 0.33 respectively.

Table 4 shows the estimated coefficients of principal components of birth weight, body mass index and maternal weight were given below. Based on Table 4 results the response variables birth weight, maternal weight and body mass index reduce from three to two without loss of information. Therefore, the new response variables are explaining $97 \%$ of variation of the original variables which expressed as linear functions of the PCA shows on Table 3. Furthermore, this study used $\mathrm{PCA}_{1}$ and $\mathrm{PCA}_{2}$ as response variables which obtain from principal component model shown below.

$P C A_{1}=-0.7$ Maternal Weight -0.7 Maternal Body Mass Index 0.1 Birth Weight

$$
P C A_{2}=
$$

-0.07 Maternal Weight -

0.07Maternal Body Mass Index - 0.99Birth Weight

From principal component model results was shows that 
mother who was increases the weight by one $\mathrm{kg}$, the mean of first and second principal components was decreased by 0.7 and 0.07 units respectively when other variable remain constant. Similarly, mother who was increase in body mass index by one $\mathrm{kg} / \mathrm{m}^{2}$, the mean of first and second principal components was decreased by 0.7 and 0.07 units respectively when other variables remain constant. In addition the first weight of baby was increases by one $\mathrm{kg}$, the mean of first and second principal components was decreased by 0.1 and 0.99 units respectively when other variable remain constant.Finally, the two principal components would be replacing three original variables without much loss of information and the original variables would be contributed for each principal component even if the contributions differ. Therefore, we determined the predictor which has effects statistically for principal components then that predictor would be effect on original variable indirectly.

\section{Bar Plot of each Component's Variance}

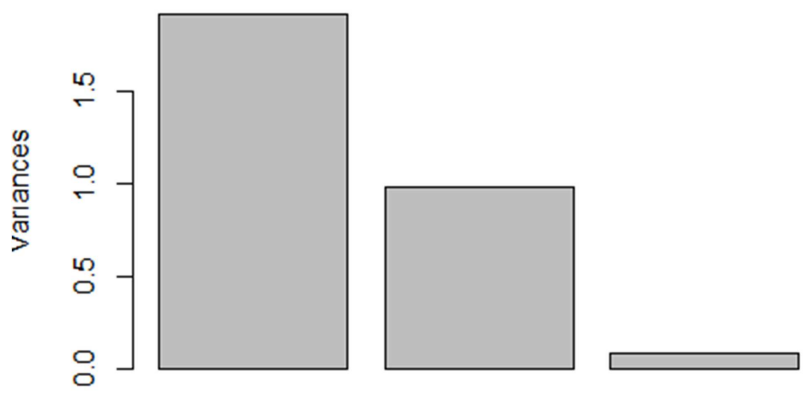

Figure 3. p\%lot of variance components.

Table 4. Principal Component Parameter Estimation.

\begin{tabular}{lll}
\hline \multirow{2}{*}{ Original Response Variable } & \multicolumn{2}{l}{ New Response Variable } \\
\cline { 2 - 3 } & PCA $_{\mathbf{1}}$ & PCA $_{\mathbf{2}}$ \\
\hline Maternal Weight & -0.70 & 0.07 \\
Maternal Body Mass Index & -0.70 & 0.07 \\
Birth Weight & -0.10 & -0.99 \\
\hline
\end{tabular}

After the overall assumptions checked and reduce the number of response variables were fit bi-variate multiple linear regression model of $\mathrm{PCA}_{1}$ and $\mathrm{PCA}_{2}$. Therefore, the significant predictors was modeled based on estimated value of the parameter that shown on Table 3 . The fitted bi-variate linear regression model that relating $\mathrm{PCA}_{1}$ and $\mathrm{PCA}_{2}$ with the explanatory variables is given as:-

$P C A_{1}=-2.01$ - 0.19family size-1.3Somali-0.77SNNP0.95Harari-1.11AddisAbaba -1.02 DireDawa+0.54 Read newspaper greater than or equal to 1week - 0.57 watch TV less 1 week - 0.9 watch TV greater than equal to 1 week -
0.97 do not known the preferred waiting time for birth of other child.

$P C A_{2}=-1.57+0.53$ larger than average size +1.02 average size +1.5 smaller than average +1.78 very small sizes +0.81 amhara +0.47 somali +0.49 gambela +0.52 addis ababa +0.63 age between 20-24

The predictor variables that accounts to explain the first and second principal components of birth weight of child, maternal body mass index and maternal weight is $81 \%$ and $80 \%$ respectively. Therefore, the model is good fit to the data.

The model parameter of first principal component interpreted as follows. The mean of $\mathrm{PCA}_{1}$ decreased by 0.19 units when household number changes by one when the effect of other variable remains constant. This result lined with the previous study [14]. In addition, the mean of $\mathrm{PCA}_{1}$ for mother who lived Somali, SNNP, Harari, AddisAbeba and DireDawa were increased by a factor 1.3, $0.77,0.95,1.11$ and 1.02 respectively as compared to mother who lived Tigray when the effect of other variable remains constant. This finding is consistent with the study by Ronnenberg et.al [1]. Furthermore, the mean of $\mathrm{PCA}_{1}$ of mother who read newspaper for greater than or equal to one per a week were increased by a factor 0.54 as compared with mothers who is not read at all when the effect of other variable remain constant. Moreover, the mean of PCA1 of mother who watch TV for less than 1 and greater than or equal to 1 per a week were decreased by factor 0.57 and 0.9 respectively as compared to not watch at all. This finding is consistent with the study by Gupta et.al [15].

The model parameter of second principal component interpreted as follows:- The mean of second principal component of mother who lived Amhara,Somali, Gambela,and AddisAbeba were increased by a factor $0.81,0.47,0.49$ and 0.52 respectively as compared to those who lived Tigray when the effect of other variable remains constant. This result in lined with the previous study byRonnenberg et.al [1]. In addition, the mean of second principal component for mother who has age between $20-24$ had increased by factor 0.63 as compared to those who had between $15-19$ when the effects of other variable remain constant. This result in lined with the previous study byRestrepo-Méndez et.al [4].

Finally, the mean of second principal components for child who had who larger than average size, average size, smaller than average and very small size increased by factor 0.53 , $1.02,1.5$ and 1.78 as compared to those who had very large size when the effect of other variable remains constant. This result in lined with the previous study by Furlong et. al [16, 17]. Bi-variate Multiple Linear Regression

Table 5. Parameter estimation of bi-variate multiple linear regression.

\begin{tabular}{llllll}
\hline PCA1 & & & PCA2 & Estimate(SE) & p- value \\
\hline Effect & Estimate(SE) & p- value & Effect & $-1.57(0.33)$ & $2.71 \mathrm{e}-06 * * *$ \\
\hline Intercept & $-2.01(0.48)$ & $3.57 \mathrm{e}-05 * * *$ & Intercept & -- & - \\
Family Size & $-0.19(0.03)$ & $2.40 \mathrm{e}-11 * * *$ & Size of child(very large=ref) & - & $0.53(0.14)$ \\
Region(Tigray=ref) & - & - & Larger than average size & $0.000129 * * *$ \\
Somali & $-1.30(0.29)$ & $8.66 \mathrm{e}-06 * * *$ & Average Size & $1.02(0.11)$ & $2 \mathrm{e}-16 * * *$ \\
\hline
\end{tabular}




\begin{tabular}{|c|c|c|c|c|c|}
\hline PCA1 & & & PCA2 & & \\
\hline Effect & Estimate(SE) & p-value & Effect & Estimate(SE) & p-value \\
\hline SNNP & $-0.77(0.26)$ & $0.00369 * *$ & Smaller than Average & $1.50(0.18)$ & $1.34 \mathrm{e}-15 * * *$ \\
\hline Harari & $-0.95(0.26)$ & $0.00028 * * *$ & Very Small Size & $1.78(0.16)$ & $2 \mathrm{e}-16 * * *$ \\
\hline Addis Ababa & $-1.11(0.24)$ & $3.96 \mathrm{e}-06 * * *$ & Region(Tigray $=$ ref) & -- & -- \\
\hline Dire dawa & $-1.02(0.24)$ & $3.87 \mathrm{e}-05 * * *$ & Amhara & $0.81(0.29)$ & $0.005384 * *$ \\
\hline Oromiya & - & - & Somali & $0.47(0.20)$ & $0.018872 *$ \\
\hline Gambela & - & - & Gambela & $0.49(0.21)$ & $0.019331 *$ \\
\hline Binishangul & - & - & Addis Ababa & $0.52(0.16)$ & $0.001499 * *$ \\
\hline Amhara & - & - & SNNP & - & - \\
\hline Afar & - & - & Harari & - & - \\
\hline Frequency of read & & & Dire dawa & - & - \\
\hline newspaper(Not at all=ref) & -- & -- & Oromiya & - & - \\
\hline$<1$ week & - & - & Binishangul & - & - \\
\hline$>=1$ week & $0.54(0.26)$ & $0.04193 *$ & Afar & - & - \\
\hline Frequency of watch TV(Not at all=ref) & & & Age Group(15-19=ref) & -- & - \\
\hline$<1$ week & -- & -- & $20-24$ & $0.63(0.24)$ & \\
\hline$>=1$ week & $-0.57(0.21)$ & $0.00648 * *$ & $25-29$ & & $0.007875 * *$ \\
\hline preferred wait time $(<1$ year=ref) & $-0.90(0.17)$ & $1.41 \mathrm{e}-07 * * *$ & $>30$ & - & \\
\hline do not known & -- & -- & & & \\
\hline $1=1$ year & $0.78(0.36)$ & $0.02996 *$ & & & \\
\hline $2=2$ year & - & & & & \\
\hline $3=3$ year & - & & & & \\
\hline $4=4$ year & - & & & & \\
\hline $5=5$ year & - & & & & \\
\hline $6=>6$ year & & & & & - \\
\hline $\mathrm{R}^{2}=0.83, \mathrm{Adj}^{2}=0.81$ & & & $\mathrm{R}^{2}=0.82, \mathrm{Adj}^{2}=0.80$ & & \\
\hline
\end{tabular}

The one dash line (-) shows insignificant variables for each response variables. The two dash line (--) shows reference category of variables.

\section{Conclusion}

Principal component analysis of birth weight of child, maternal pregnancy weight and maternal pregnancy body mass index reveals $97 \%$ of the variation account by the first two principal components. The first and second principal component were required to have proportion of variance would be 0.64 and 0.33 respectively. Therefore, this study discussed on the effect of explanatory variables when the principal component analysis of birth weight of child, maternal pregnancy weight and maternal pregnancy body mass index were fitted jointly.

This study determines the factors that affect the first two principal componentsof birth weight of child, maternal pregnancy weight and maternal pregnancy body mass indexamong pregnant women in Ethiopia simultaneously. Therefore, family size, region, frequency of read newspaper, frequency of watch television and preferred waiting time for birth were statistically significant at $5 \%$ level of significance for first principal component in Ethiopia. Furthermore,size of child, region and maternal age group are statistically significant at $5 \%$ level of significance for second principal components of birth weight of child, maternal pregnancy weight and maternal pregnancy body mass index in Ethiopia. From the result of the study shows that the first principal componentincreased when family size decreased in the household. However, the family size decreased in the household then birth weight of child, maternal weight and maternal body mass indexwere decreased.
Furthermore,the first principal components of mother who live Somali, SNNP, Hrari,Adiss Ababa and Dire Dawa decreased as compared those who lived Tigray. But the birth weight of child, maternal pregnancy weight and body mass index were increased. In addition, the first principal component of mother who is read newspaper more than 1 times per a week were increased as compared to those who are not read at all implies birth weight of child, maternal body mass index and maternal weight decreased. Moreover, the first principal components of mother who watch TV were increased as compared to those who is not watch at all implies birth weight,bodymass index and maternal weight were decreased.

Finally, the second principal components of mother who live Somali,Amhara, Gambela and Adiss Ababa increased as compared those who lived Tigray even if the size of child and the age of mother different implies except birth weight of child maternal pregnancy weight and maternal body mass index were increased.

\section{Appendix}

$R$-codes for data Analysis

attach(data name)

names(data name)

library(MASS)

library $(M V N)$

$M W=$ data name \$maternal_weight

$B M I=$ data name $\$ N e B M I$

$B W=$ data name $\$ N e B W$ 
datal $=$ data.frame $(M W, B M I, B W)$

$h<-\operatorname{prcomp}($ datal, scale $=T)$

summary $(h)$

$P C A 1<-h \$ x[, 1]$

$P C A 2=h \$ x[, 2]$

$m=\operatorname{cbind}(P C A 1, P C A 2)$

$\bmod 1<-$

Im( $m \sim$ as.factor(Size_child) + as.factor(number_befpre $)+$ as.fa ctor(Region) + as. factor(frequency read news) + as.factor(fre q_watch television) + familiy_size + as.factor(husband partne $r$ _edu_le) + as.factor(Preferred) + as.factor(age_group) + as.fa ctor(desire))

summary $(\bmod 1)$

plot(fitted $(\bmod 1)$, resid(mod1), col = "dodgerblue",

pch $=20$, cex $=1.5, \quad x l a b=$ "Fitted", ylab =

"Residuals", main = "Fitted vs Residual Plot")

abline $(h=0$, lty $=2$, col = "darkorange", lwd =2)

qqnorm(resid(mod1), main = "Normal Q-Q Plot", col = "darkgrey")

qqline(resid(mod1), col = "dodgerblue", lwd =2)

\section{Abbreviation}

LBW: Low Birth Weight; BMI: Body Mass Index;TV: Television; DHS: Demographic andhealth survey; SNNPR: Southern Nations Nationality and peoples Region; EDHS: Ethiopia demographic and health survey; $\mathrm{R}^{2}$ : Coefficient of determination; PCA: Principal Component Analysis;SD: Standard Deviation

\section{Funding}

Haramaya University

\section{Availability of Data and Material}

The raw data used in this study can be accessed from the DHS website: http://www.dhsmeasures.

\section{Authors' Contributions}

KK have made substantial contribution to conception, design, analysis and interpretation of data and involved in drafting the manuscript, revising it critically for important intellectual content and all have given final approval of the version to be published.

\section{Ethics Approval and Consent to Participate}

Letter of consent was received from the Measure EDHS International Program, which authorized the data sets.All the data that used in this study are publicly available and do not in any allow respondents, households, or sample communities to be identified.Confidentiality of data maintained anonymously.

\section{Consent for Publication}

Not applicable.

\section{Competing Interests}

The authors declare that they have no competing interests.

\section{Acknowlegements}

Ethiopia Demography Health Survey and Haramaya University, Ethiopia, is gratefully acknowledged for the data and financial support respectively. My wife Frahiwot Geira and My little child Meklit Kindu are also highly acknowledged for motivation to write this manuscript related to creativity of happiness with in my mind.

\section{References}

[1] RonnenbergAG,Wang, XingH, ChenC, ChenD, Guang W, GuangA, WangL, RyanL,XuX, Low preconception body mass index is associated with birth outcome in a prospective cohort of Chinese women. The Journal of nutrition. 2003 Nov 1; 133 (11): 3449-55.

[2] Akgun N, Keskin HL, Ustuner I, Pekcan G, Avsar AF. Factors affecting pregnancy weight gain and relationships with maternal/fetal outcomes in Turkey. Saudi medical journal. 2017 May; 38 (5): 503.

[3] Dönmez S, Güner Ö. Relationship Between Weight PrePregnancy and Weight Gain During Pregnancy with Preterm Birth. J Nutr Health Sci. 2017; 4 (2): 204.

[4] Restrepo-Méndez MC, Lawlor DA, Horta BL, Matijasevich A, Santos IS, Menezes AM, Barros FC, Victora CG. The association of maternal age with birthweight and gestational age: a cross-cohort comparison. Paediatric and perinatal epidemiology. 2015 Jan; 29 (1): 31-40.

[5] Auger N, Authier MA, Martinez J, Daniel M. The association between rural-urban continuum, maternal education and adverse birth outcomes in Quebec, Canada. The Journal of Rural Health. 2009 Sep; 25 (4): 342-51.

[6] Siza JE. Risk factors associated with low birth weight of neonates among pregnant womenattending a referral hospital in northern Tanzania. Tanzania journal of health research. 2008; 10 (1): 1-8.

[7] Kastro S, Demissie T, Yohannes B. Low birth weight among term newborns in Wolaita Sodo town, South Ethiopia: a facility based cross-sectional study. BMC pregnancy and childbirth. 2018 Dec; 18 (1): 160.

[8] CSA I. Ethiopia demographic and health survey 2011. Addis Ababa, Ethiopia and Calverton, Maryland, USA: Central Statistical Agency and ICF International. 2012; 430.

[9] Kanagalingam MG, Forouhi NG, Greer IA, Sattar N. Changes in booking body mass index over a decade: retrospective analysis from a Glasgow Maternity Hospital. BJOG: An International Journal of Obstetrics \& Gynaecology. 2005 Oct; 112 (10): 1431-3. 
[10] Lu GC, Rouse DJ, DuBard M, Cliver S, Kimberlin D, Hauth JC. The effect of the increasing prevalence of maternal obesity on perinatal morbidity. American journal of obstetrics and gynecology. 2001 Oct 1; 185 (4): 845-9.

[11] Gunderson EP. Childbearing and obesity in women: weight before, during, and after pregnancy. Obstetrics and Gynecology Clinics. 2009 Jun 1; 36 (2): 317-32.

[12] Nkurunziza S, Ejaz Ahmed S. Estimation strategies for the regression coefficient parameter matrix in multivariate multiple regression. Statistica Neerlandica. 2011 Nov; 65 (4): 387-406.

[13] Johnson RA, Wichern DW. Applied multivariate statistical analysis. Upper Saddle River, NJ: Prentice hall; 2002.

[14] Datar A. The more the heavier? Family size and childhood obesity in the US. Social Science \& Medicine. 2017 May 1; 180: 143-51.

[15] Gupta RD, Sajal IH, Hasan M, Sutradhar I, Haider MR, Sarker M. Frequency of television viewing and association with overweight and obesity among women of the reproductive age group in Myanmar: results from a nationwide cross-sectional survey. BMJ open. 2019 Mar 1; 9 (3): e024680.

[16] Eide MG, Øyen N, Skjœrven R, Nilsen ST, Bjerkedal T, Tell GS. Size at birth and gestational age as predictors of adult height and weight. Epidemiology. 2005 Mar 1: 175-81.

[17] Furlong KR, Anderson LN, Kang H, Lebovic G, Parkin PC, Maguire JL, O'Connor DL, Birken CS, TARGet Kids! Collaboration. BMI-for-age and weight-for-length in children 0 to 2 years. Pediatrics. 2016 Jul 1; 138 (1): e20153809. 